\title{
Degradation of $\beta$-blockers in water by sulfate radical-based oxidation: kinetics, mechanism and ecotoxicity assessment
}

\author{
K. S. Tay ${ }^{1}$ N. S. B. Ismail ${ }^{1}$
}

Received: 21 January 2016/Revised: 23 June 2016/Accepted: 23 July 2016/Published online: 12 August 2016

(C) Islamic Azad University (IAU) 2016

\begin{abstract}
This study investigated the kinetics and degradation pathway of acebutolol, metoprolol and sotalol in a sulfate radical-based advanced oxidation process. The selected pharmaceuticals were $\beta$-blockers which have been used to treat cardiovascular diseases. Due to its frequent use, the presence of these pharmaceuticals in the environment has been regularly reported. In this study, sulfate radicals were generated using peroxymonosulfate with cobalt (II) as activator. At $\mathrm{pH} 7$ and $25^{\circ} \mathrm{C}$, the secondorder rate constant for the reaction between $\mathrm{SO}_{4}{ }^{-}$with metoprolol, acebutolol and sotalol was $(1.0 \pm 0.1) \times 10^{10}$, $(2.0 \pm 0.1) \times 10^{10}$ and $(3.0 \pm 0.2) \times 10^{10} \mathrm{M}^{-1} \mathrm{~s}^{-1}$, respectively. Sixteen transformation by-products were identified from the selected $\beta$-blockers. These transformation by-products were mainly formed through the hydroxylation, aromatic ring-opening reaction and aliphatic chain oxidation. The decomposition of $\beta$-blockers by sulfate radicals was found to start from the formation of hydroxylated $\beta$-blockers followed by an aromatic ring-opening reaction. In general, this study showed that $\beta$-blockers reacted favorably with sulfate radicals, and various transformation by-products could be produced. The result from the ecotoxicity assessment showed that almost all of the transformation by-products were less toxic than its parent
\end{abstract}

Editorial responsibility: J. Aravind.

Electronic supplementary material The online version of this article (doi:10.1007/s13762-016-1083-3) contains supplementary material, which is available to authorized users.

\section{K. S. Tay}

khengsoo@um.edu.my

1 Environmental Research Group, Department of Chemistry, Faculty of Science, University of Malaya, 50603 Kuala Lumpur, Malaysia compound. Therefore, a sulfate radical-based advanced oxidation process could be an effective method for the treatment of $\beta$-blockers in water.

Keywords Acebutolol · Metoprolol - Sotalol · Advanced oxidation process - Water treatment - Transformation byproducts

\section{Introduction}

Recently, the presence of pharmaceuticals as emerging pollutants has attracted much attention due to its potential adverse health effects to living organisms (Cizmas et al. 2015; Bundschuh et al. 2016). The negative impacts of environmental pharmaceuticals are such as endocrine disrupting effect on fish (Sun et al. 2016); inhibition of the growth of aquatic plants (Pomati et al. 2004); producing antibiotic resistant bacteria (Cizmas et al. 2015); and intersex and reduced fecundity in fish (Niemuth and Klaper 2015). Each year, thousands of tons of pharmaceuticals are prescribed and consumed worldwide (Burkina et al. 2015). As a result, pharmaceuticals have been frequently detected in the environment. So far, the effluents of wastewater treatment plants (WWTPs) have been identified as the major sources of pharmaceuticals in the environment. This is mainly due to the inefficiency of WWTPs in the treatment of these emerging pollutants (Burkina et al. 2015).

Among various classes of environmental pharmaceuticals, $\beta$-blockers have been frequently detected in various aquatic environments (Liu et al. 2015; Sun et al. 2015, Santos et al. 2013). $\beta$-Blockers are pharmaceuticals used to treat cardiovascular diseases (Huggett et al. 2003). The removal of $\beta$-blockers by some of the WWTPs was relatively poor (Santos et al. 2013). As a result, the presence of 
$\beta$-blockers in the environment with concentrations in $\mu \mathrm{g} / \mathrm{L}$ has been reported (Maszkowska et al. 2014a). Although $\beta$ blockers are safe for humans, some of the $\beta$-blockers are harmful to some aquatic organisms (Maszkowska et al. 2014b).

Recently, a sulfate radical-based advanced oxidation process (SR-AOP) has been reported as an effective chemical oxidation method for the removal of pharmaceuticals (Gao et al. 2015; Ji et al. 2015; Zhang et al. 2015; $\mathrm{Ji}$ et al. 2016a). Sulfate radicals $\left(\mathrm{SO}_{4}{ }^{-}\right)$react with organic compounds at the rate of $10^{7}$ to $10^{10} \mathrm{M}^{-1} \mathrm{~s}^{-1}$ (Matta et al. 2011). As compared to hydroxyl radicals $(\cdot \mathrm{OH}), \mathrm{SO}_{4}{ }^{-}$ with a more selective nature reacts with organic compounds mainly through electron transfer reaction (Anipsitakis et al. 2006). However, non-selective $\cdot \mathrm{OH}$ reacts reactively with almost all organic compounds, but it can be inactivated easily by the water matrices (Matta et al. 2011). So far, SR-AOP has been employed in the treatment of soils and groundwater (Tsitonaki et al. 2010). Therefore, it is important to study the fate of pharmaceuticals in SRAOP since some of the commonly used oxidation processes could produce transformation by-products which are more toxic than its parent compound (Tay and Madehi 2014).

The main objectives of this study were (1) to determine the second-order rate constant for the reaction between $\mathrm{SO}_{4}{ }^{-}$and selected $\beta$-blockers; (2) to identify the transformation by-products and to elaborate the degradation pathway of $\beta$-blockers during SR-AOP; and (3) to assess the ecotoxicity of the transformation by-products. The selected $\beta$-blockers were sotalol, acebutolol and metoprolol. Based on the literature review, the degradation of the $\beta$ blockers in various chemical oxidation processes such as ozonation (Benner et al. 2008; Tay et al. 2013; Tay and Madehi 2014), OH-based AOP (Veloutsou et al. 2014; Romero et al. 2015) and chlorination (Khalit and Tay 2016) have been widely reported. However, the fate of the selected $\beta$-blockers in SR-AOP has not been reported elsewhere. In this study, the ecotoxicity of transformation by-products was evaluated using computational method. Based on the literature review, ecotoxicity of transformation by-products generated from SR-AOP was seldom reported. This study was carried out at the Department of Chemistry, Faculty of Science, University of Malaya (Malaysia), from December 2014 to May 2015.

\section{Materials and methods}

\section{Chemicals and reagent}

Acebutolol hydrochloride, metoprolol tartrate salt, sotalol hydrochloride, benzoic acid and formic acid were obtained from Sigma. Potassium peroxymonosulfate (PMS) and cobalt (II) sulfate heptahydrate $\left(\mathrm{CoSO}_{4} \cdot 7 \mathrm{H}_{2} \mathrm{O}\right)$ were purchased from Acros Organics. HPLC-grade methanol was purchased from RCI Labscan (Thailand). HPLC-grade acetonitrile was obtained from Merck (Germany). Tertbutanol, disodium hydrogen phosphate dehydrate were supplied by Riedel-de Haën (Germany), and sodium dihydrogen phosphate monohydrate was obtained from Aldrich (USA). All stock solutions were prepared in ELGA ultrapure water. Freshly prepared PMS and cobalt (II) sulfate heptahydrate solutions were used for the study.

\section{Determination of second-order rate constant}

Competition kinetics method was used to determine the second-order rate constant $\left(K_{\text {app }}\right)$ for the reaction between the selected $\beta$-blockers and $\mathrm{SO}_{4}{ }^{-}$. In this study, benzoic acid was used as reference compound. The reported second-order rate constant for the reaction between benzoic acid with $\mathrm{SO}_{4}{ }^{-}$was $1.2 \times 10^{9} \mathrm{M}^{-1} \mathrm{~s}^{-1}$ (Guan et al. 2011). The experiment was conducted as reported in previous studies (Matta et al. 2011; Ji et al. 2016b) with slight modification. Briefly, the kinetic experiments were conducted in a $50-\mathrm{mL}$ jacketed beaker containing the selected $\beta$-blocker, benzoic acid and cobalt (II) sulfate with the concentration of $100 \mu \mathrm{M}$ each. The $\mathrm{pH}$ of the reaction mixture was adjusted to 7 with $50 \mathrm{mM}$ of phosphate buffer, and the temperature was set at $25^{\circ} \mathrm{C}$. The solution was stirred throughout the experiment by using a magnetic stirrer. The reaction was then initiated by adding $1000 \mu \mathrm{M}$ of PMS solution, and the final volume of the reaction mixture was $50 \mathrm{~mL}$. Every $5 \mathrm{~s}, 1 \mathrm{~mL}$ of aliquot was withdrawn from reaction mixture and the reaction was quenched with $100 \mu \mathrm{L}$ of methanol. The concentration of selected $\beta$-blocker and benzoic acid contained in the aliquot was determined using HPLC.

\section{By-product identification}

The transformation by-products of the selected $\beta$-blockers were produced using PMS with and cobalt (II) sulfate as activator. The molar ratio of the selected $\beta$-blockers to PMS was set at 1:10, and the $\mathrm{pH}$ of the solution was adjusted to 7 using phosphate buffer; $1 \mathrm{~mL}$ of reaction mixture was withdrawn every $10 \mathrm{~s}$, and the reaction was quenched with $100 \mu \mathrm{L}$ methanol. The mixture was then analyzed using liquid chromatography quadrupole time-offlight mass spectrometry (LC-QTOF-MS).

\section{Instrumental analysis}

For kinetics study, the concentration of selected $\beta$-blockers and benzoic acid was monitored using a HPLC system (Shimadzu, Japan) which consisted of a LC-20AT pump, a 
SPD-M20A diode array detector, a SIL-20AHT autosampler and a CTO-10AS column oven. A reversed-phase Chromolith RP-18 monolithic column (100 mm $\times 4.6 \mathrm{~mm}$; Merck, Germany) was used for separation. The identification of by-products was performed using a 6500 accurate mass quadrupole time-of-flight mass spectrometer bearing with electrospray ionization source coupled to a 1200 series rapid resolution LC system (LCQTOFMS, Agilent Technologies, Santa Clara, USA) as reported by Tay et al. (2013).

\section{Ecotoxycity assessment}

Ecotoxicity of transformation by-products was assessed using Ecological Structure-Activity Relationship Model (ECOSAR) software (version 1.1) as reported by a previous study (Tay and Madehi 2015).

\section{Results and discussion}

\section{Kinetics study}

In this study, $K_{\text {app }}$ was determined using the competitive kinetics method. This method has been used to determine the $K_{\text {app }}$ for various organic pollutants such as carbamazepine (Matta et al. 2011) and caffeic acid (Swaraga and Adinarayana 2003). The concept of this method is based on the simultaneous oxidation of the reference compound and the selected $\beta$-blockers. In this case, the $K_{\text {app }}$ for the reaction between reference compound with $\mathrm{SO}_{4}{ }^{-}\left[K_{\text {app }}\right.$ (reference) $]$ is known, and the $K_{\text {app }}$ for the reaction between $\mathrm{SO}_{4}{ }^{-}$with selected $\beta$-blockers $\left[K_{\text {app }}(\beta\right.$ blocker)] was determined using the following equation ( $\mathrm{Ji}$ et al. 2016b):

$\ln \left(\frac{[\beta-\text { blocker }]_{t}}{[\beta \text {-blocker }]_{0}}\right)=\frac{K_{\text {app }}(\beta-\text { blocker })}{K_{\text {app }}(\text { reference })} \ln \left(\frac{[\text { reference }]_{t}}{[\text { reference }]_{0}}\right)$

For this study, benzoic acid was selected as the reference compound, and the plot for the $K_{\text {app }}$ determination is presented in Fig. 1 . The determined $K_{\text {app }}$ values for the selected $\beta$-blockers are presented in Table 1 . The result indicated that at $\mathrm{pH} 7$ and $25^{\circ} \mathrm{C}$, metoprolol, acebutolol and sotalol reacted with $\mathrm{SO}_{4}{ }^{-}$at the rate of $(1.0 \pm 0.1) \times 10^{10}, \quad(2.0 \pm 0.1) \times 10^{10}$ and $\quad(3.0 \pm$ $0.2) \times 10^{10} \mathrm{M}^{-1} \mathrm{~s}^{-1}$, respectively.

\section{Degradation by-products}

For the selected $\beta$-blockers, sixteen transformation byproducts were identified. The transformation by-products of acebutolol, metoprolol and sotalol are presented in Tables 2, 3 and 4, respectively. MSMS spectrum of

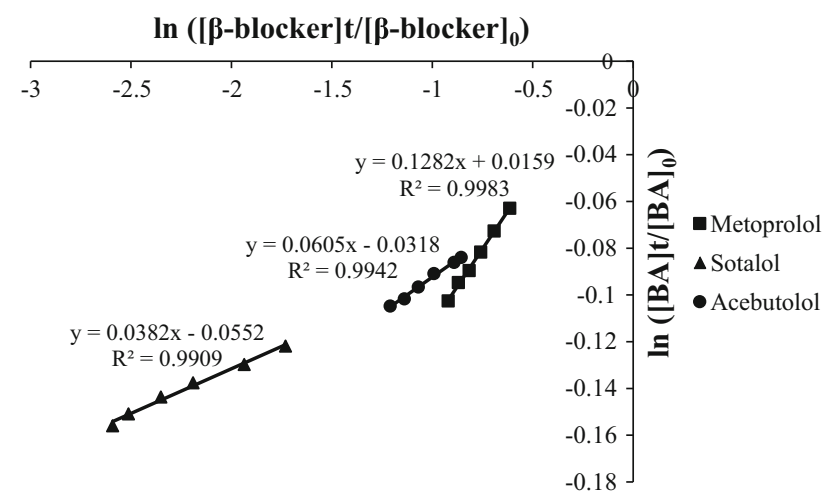

Fig. 1 Plot for the determination of $K_{\text {app }}$ for the reaction of selected $\beta$-blockers with $\mathrm{SO}_{4}{ }^{-}$

Table 1 Determined $K_{\text {app }}$ for the reaction between selected $\beta$ blockers with $\mathrm{SO}_{4}{ }^{-}$

\begin{tabular}{ll}
\hline$\beta$-blockers & $K_{\text {app }}\left(\mathrm{M}^{-1} \mathrm{~s}^{-1}\right)$ \\
\hline Metoprolol & $(1.0 \pm 0.1) \times 10^{10}$ \\
Acebutolol & $(2.0 \pm 0.1) \times 10^{10}$ \\
Sotalol & $(3.0 \pm 0.2) \times 10^{10}$ \\
\hline
\end{tabular}

selected $\beta$-blockers and its transformation by-products are presented in Supplementary Material (Figs. S1-S3). These degradation by-products can be categorized as hydroxylated, aliphatic chain-oxidized and aromatic ring-degraded by-products. For acebutolol, two aromatic ring-hydroxylated by-products (Ace-368 and Ace-386) were detected. Ace-368 with the quasimolecular ion $\left([\mathrm{M}+\mathrm{H}]^{+}\right)$peak at $\mathrm{m} / \mathrm{z} 369.2045$ (Fig S1) showed additional 32 amu as compared with the $[\mathrm{M}+\mathrm{H}]^{+}$ion of acebutolol, indicating the presence of two hydroxyl $(\mathrm{OH})$ groups (Table 2). On the other hand, the $[\mathrm{M}+\mathrm{H}]^{+}$ion of Ace-386 showed additional $49 \mathrm{amu}$ attributed to the addition of three $\mathrm{OH}$ groups and one hydrogen atom to acebutolol. In order to add a hydrogen atom, two $\mathrm{OH}$ groups are proposed to be added to a carbon atom at the aromatic ring for the formation of a hexacyclodienyl ring. For metoprolol, two aromatic ring-hydroxylated by-products were identified. Met-299 is an aromatic ring-dihydroxylated metoprolol (Table 3, Fig S2). Similar to Ace-386, Met-317 is also a trihydroxylated metoprolol with additional one hydrogen atom. For sotalol, hydroxylation reaction produced tetrahydroxylated sotalol, Sot-336 (Table 4). The mechanism for the formation of aromatic ring-hydroxylated $\beta$ blockers is proposed to start from the addition of a sulfate group to the aromatic ring of $\beta$-blockers to form intermediate $I$ (Fig. 2). Sulfate group is a good leaving group. Therefore, intermediate $\boldsymbol{I}$ tends to rearrange, through the elimination of the sulfate group, to form radical cation $\boldsymbol{I I}$ (Anipsitakis et al. 2006). Then, hydrolysis of radical cation II leads to the formation of hydroxylated hexacyclodienyl 
Table 2 Acebutolol and its proposed transformation by-products

\begin{tabular}{|c|c|c|c|c|c|}
\hline $\begin{array}{l}\text { Elemental composition } \\
\text { of }[\mathrm{M}+\mathrm{H}]^{+}\end{array}$ & $\begin{array}{l}\text { Proposed structure } \\
\text { (Label) }\end{array}$ & $\begin{array}{l}\text { Major fragment in } \\
\text { MS/MS spectrum }\end{array}$ & $\begin{array}{l}\text { Measured exact } \\
\text { mass }\end{array}$ & $\begin{array}{l}\text { Calculated } \\
\text { exact mass }\end{array}$ & $\begin{array}{l}\text { Mass error } \\
(\mathrm{ppm})\end{array}$ \\
\hline $\mathrm{C}_{18} \mathrm{H}_{29} \mathrm{~N}_{2} \mathrm{O}_{4}^{+}$ & Acebutolol & $\begin{array}{l}m / z 337.2118^{\mathrm{a}} \\
\mathrm{m} / \mathrm{z} 319.2016 \\
\mathrm{~m} / \mathrm{z} 260.1280 \\
\mathrm{~m} / \mathrm{z} 218.1176 \\
\mathrm{~m} / \mathrm{z} 116.1073\end{array}$ & 336.2050 & 336.2049 & 0.30 \\
\hline $\mathrm{C}_{10} \mathrm{H}_{20} \mathrm{NO}_{4}^{+}$ & Ace-217 & $\begin{array}{ll}m / z & 218.1378^{\mathrm{a}} \\
\mathrm{m} / \mathrm{z} & 200.1296 \\
\mathrm{~m} / \mathrm{z} & 158.0772 \\
\mathrm{~m} / \mathrm{z} & 134.1168 \\
\mathrm{~m} / \mathrm{z} & 116.1071\end{array}$ & 217.1314 & 217.1314 & 0 \\
\hline $\mathrm{C}_{14} \mathrm{H}_{22} \mathrm{NO}_{3}{ }^{+}$ & Ace-251 & 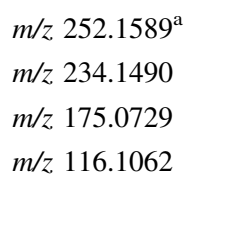 & 251.1517 & 251.1521 & -1.60 \\
\hline $\mathrm{C}_{16} \mathrm{H}_{27} \mathrm{~N}_{2} \mathrm{O}_{5}^{+}$ & Ace-326 & 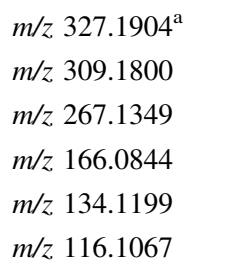 & 326.1843 & 326.1842 & 0.31 \\
\hline $\mathrm{C}_{18} \mathrm{H}_{29} \mathrm{~N}_{2} \mathrm{O}_{6}^{+}$ & $\begin{array}{c}(\mathrm{HO})_{2} \\
\text { Ace- } 368\end{array}$ & $\begin{array}{l}m / z 369.2045^{\mathrm{a}} \\
m / z 351.1884 \\
m / z\end{array}$ & 368.1947 & 368.1947 & 0 \\
\hline $\mathrm{C}_{18} \mathrm{H}_{31} \mathrm{~N}_{2} \mathrm{O}_{7}^{+}$ & Ace-386 & 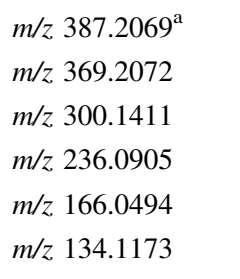 & 386.2046 & 386.2053 & -1.81 \\
\hline $\mathrm{C}_{16} \mathrm{H}_{27} \mathrm{~N}_{2} \mathrm{O}_{6}^{+}$ & Ace-342 & 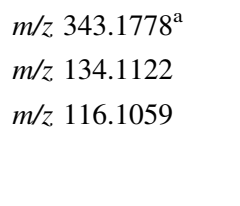 & 342.1795 & 342.1791 & 1.17 \\
\hline
\end{tabular}

${ }^{\mathrm{a}}[\mathrm{M}+\mathrm{H}]^{+}$ion

radical III. Reaction between $\boldsymbol{I I I}$ and $\mathrm{O}_{2}$ may give rise to the peroxyl radical $(\boldsymbol{I} \boldsymbol{V})$ which could decompose to form monohydroxylated $\beta$-blockers $(\boldsymbol{V})$. Further hydroxylation of $\boldsymbol{V}$ forms the dihydroxylated $\beta$-blockers. The formation of Met-317 and Ace-368 is proposed to start from the electron transfer from the aromatic ring of dihydroxylated $\beta$-blockers (Met-299 and Ace-368) to $\mathrm{SO}_{4}{ }^{-}$for the formation of radical cation $\boldsymbol{V I}$ (Fig. 3). The reaction between the water molecule and $\boldsymbol{V I}$ leads to the formation of trihydroxylated hexacyclodienyl radical VII. VII may react with peroxyl radical for the formation of Met-317 and Ace368. 
Table 3 Metoprolol and its proposed transformation by-products

\begin{tabular}{|c|c|c|c|c|c|}
\hline $\begin{array}{l}\text { Elemental composition } \\
\text { of }[\mathrm{M}+\mathrm{H}]^{+}\end{array}$ & $\begin{array}{l}\text { Proposed structure } \\
\text { (Label) }\end{array}$ & $\begin{array}{l}\text { Major fragment in } \\
\text { MS/MS spectrum }\end{array}$ & $\begin{array}{l}\text { Measured } \\
\text { exact mass }\end{array}$ & $\begin{array}{l}\text { Calculated } \\
\text { exact mass }\end{array}$ & $\begin{array}{l}\text { Mass error } \\
(\mathrm{ppm})\end{array}$ \\
\hline $\mathrm{C}_{15} \mathrm{H}_{26} \mathrm{NO}_{3}^{+}$ & Metoprolol & $\begin{array}{ll}m / z & 268.1930^{\mathrm{a}} \\
m / z & 226.1453 \\
m / z & 191.1082 \\
m / z & 159.0819 \\
m / z & 116.1083\end{array}$ & 267.1850 & 267.1834 & 5.99 \\
\hline $\mathrm{C}_{8} \mathrm{H}_{18} \mathrm{NO}_{4}^{+}$ & Met-191 & 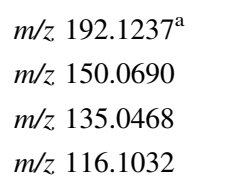 & 191.1176 & 191.1158 & 9.41 \\
\hline $\mathrm{C}_{10} \mathrm{H}_{18} \mathrm{NO}_{5}^{+}$ & Met-231 & 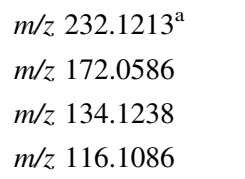 & 231.1133 & 231.1107 & 11.3 \\
\hline $\mathrm{C}_{15} \mathrm{H}_{26} \mathrm{NO}_{6}{ }^{+}$ & Met-317 & 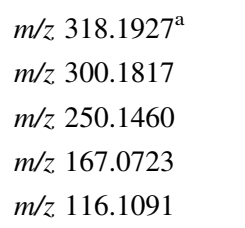 & 317.1837 & 317.1838 & -0.32 \\
\hline $\mathrm{C}_{15} \mathrm{H}_{26} \mathrm{NO}_{5}^{+}$ & Met-299 & 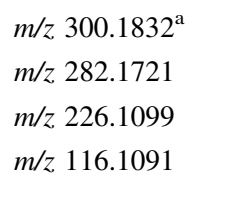 & 299.1766 & 299.1733 & 11.0 \\
\hline $\mathrm{C}_{12} \mathrm{H}_{20} \mathrm{NO}_{3}^{+}$ & Met-225 & $\begin{array}{ll}m / z & 226.1430^{\mathrm{a}} \\
m / z & 184.1003 \\
m / z & 149.0612 \\
m / z & 123.0433\end{array}$ & 225.1385 & 225.1365 & 8.88 \\
\hline
\end{tabular}

a $[\mathrm{M}+\mathrm{H}]^{+}$ion

Ace-251 and Met-225 are the transformation by-products formed through the removal of butylamide and the methoxyethyl groups from acebutolol and metoprolol, respectively. By using Met-225 as an example, the hydroxylation followed by the removal of methoxyethyl chain from metoprolol is proposed to start from the addition of $\mathrm{SO}_{4}{ }^{-}$to the aromatic ring of metoprolol for the formation of radical VIII (Fig. 4). Elimination of sulfate group from radical VIII leads to the formation of radical cation $\boldsymbol{I} \boldsymbol{X}$. IX can further react with water to form radical $\boldsymbol{X}$. Radical $\boldsymbol{X}$ could rearrange and react with peroxyl radical to form Met-225. Ace-326 and Ace-342 are hydroxylated by-products which formed after the deacetylation of acebutolol.
The reaction at the aromatic rings of metoprolol and acebutolol was also found to produce aromatic ring-opening by-products. Ace-217, Met-191 and Met-231 were the detected aromatic ring-opening by-products for acebutolol and metoprolol, respectively. The formation of aromatic ring-opening by-products also has been reported by $\mathrm{Xu}$ et al. (2013) in the degradation of 2,4,6-trichlorophenol by using $\mathrm{SO}_{4}{ }^{-}$. The cleavage of the aromatic ring is proposed to start from the formation of quinone intermediates from the dihydroxylated species. These quinone intermediates were then subjected to the nucleophilic attack and hydrogen abstraction by $\mathrm{SO}_{4}{ }^{-}$for the breakdown of the carboncarbon bond of aromatic ring ( $\mathrm{Xu}$ et al. 2013). Aromatic ring-opening reaction is an important pathway that leads to 
Table 4 Sotalol and its proposed transformation by-products

\begin{tabular}{|c|c|c|c|c|c|}
\hline $\begin{array}{l}\text { Elemental composition } \\
\text { of }[\mathrm{M}+\mathrm{H}]^{+}\end{array}$ & $\begin{array}{l}\text { Proposed structure } \\
\text { (Label) }\end{array}$ & $\begin{array}{l}\text { Major fragment in } \\
\text { MS/MS spectrum }\end{array}$ & $\begin{array}{l}\text { Measured } \\
\text { exact mass }\end{array}$ & $\begin{array}{l}\text { Calculated } \\
\text { exact mass }\end{array}$ & $\begin{array}{l}\text { Mass error } \\
(\mathrm{ppm})\end{array}$ \\
\hline $\mathrm{C}_{12} \mathrm{H}_{21} \mathrm{~N}_{2} \mathrm{O}_{3} \mathrm{~S}^{+}$ & Sotalol & 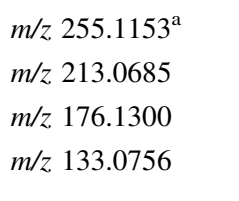 & 272.1189 & 272.1195 & -2.20 \\
\hline $\mathrm{C}_{12} \mathrm{H}_{21} \mathrm{~N}_{2} \mathrm{O}_{7} \mathrm{~S}^{+}$ & Sot-336 & 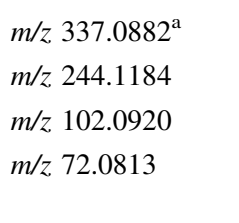 & 336.0987 & 336.0991 & -1.19 \\
\hline $\mathrm{C}_{12} \mathrm{H}_{19} \mathrm{~N}_{2} \mathrm{O}_{7} \mathrm{~S}^{+}$ & $\begin{array}{c}\mathrm{OH} \text { OH } \\
\text { Sot-334 }\end{array}$ & 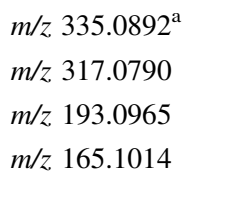 & 334.0854 & 334.0835 & 5.69 \\
\hline $\mathrm{C}_{12} \mathrm{H}_{19} \mathrm{~N}_{2} \mathrm{O}_{6} \mathrm{~S}^{+}$ & Sot-318 & 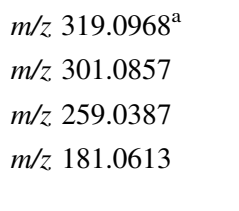 & 318.0897 & 318.0886 & 3.46 \\
\hline $\mathrm{C}_{11} \mathrm{H}_{17} \mathrm{~N}_{2} \mathrm{O}_{4}^{+}$ & Sot- 240 & 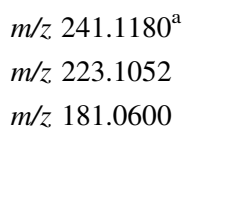 & 240.1114 & 240.1110 & 1.67 \\
\hline $\mathrm{C}_{11} \mathrm{H}_{17} \mathrm{~N}_{2} \mathrm{O}_{3}{ }^{+}$ & Sot-224 & 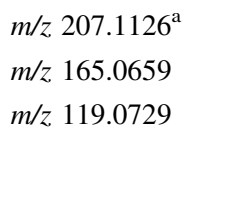 & 224.1162 & 224.1161 & 0.45 \\
\hline
\end{tabular}

a $[\mathrm{M}+\mathrm{H}]^{+}$ion

the mineralization of organic compounds in oxidation processes.

$\mathrm{SO}_{4}{ }^{-}$- was also found to react with the aliphatic chain of sotalol. This reaction yielded 4 products Sot-334, Sot-318, Sot-240 and Sot-224. Sot-240 and Sot-224 are the transformation by-products without methane sulfonyl group. The $[\mathrm{M}+\mathrm{H}]^{+}$ion of Sot-334 and Sot-318 was found to be 2 amu lower than the tetra- and trihydroxylated sotalol (Fig S3). This result suggested that these by-products were formed through the loss of 2 hydrogen atoms from 1-(isopropylamino)propan-2-ol chain of tetra- and trihydroxylated sotalol. By using Sot-318 as an example, the mechanism for the oxidation of 1-(isopropylamino)propan- 2-ol chain is proposed to start from the transfer of an electron from the amino group to $\mathrm{SO}_{4}{ }^{-}$for the formation of radical cation $\boldsymbol{X I}$ (Fig. 5). Deprotonation of $\boldsymbol{X I}$ leads to the formation of radical $\boldsymbol{X I I}$ (Xu et al. 2013), which could be further converted to Sot-334 and Sot-318. Based on the proposed transformation by-products, it can be concluded that during $\mathrm{SR}-\mathrm{AOP}, \mathrm{SO}_{4}{ }^{-}$reacts selectively with $\beta$ blockers at the aromatic ring and the secondary amine group. The reactions between $\cdot \mathrm{OH}$ with $\beta$-blockers have been widely reported (Tay et al. 2011, 2013; Veloutsou et al. 2014). Non-selective $\cdot \mathrm{OH}$ were reported to react at both aliphatic chains and the aromatic ring of $\beta$-blockers. Consequently, more diverse transformation by-products 
Fig. 2 Proposed mechanism for the formation dihydroxylated $\beta$ blockers through hydroxylation reaction

Fig. 3 Proposed mechanism for the formation of trihydroxylated $\beta$-blockers through hydroxylation reaction

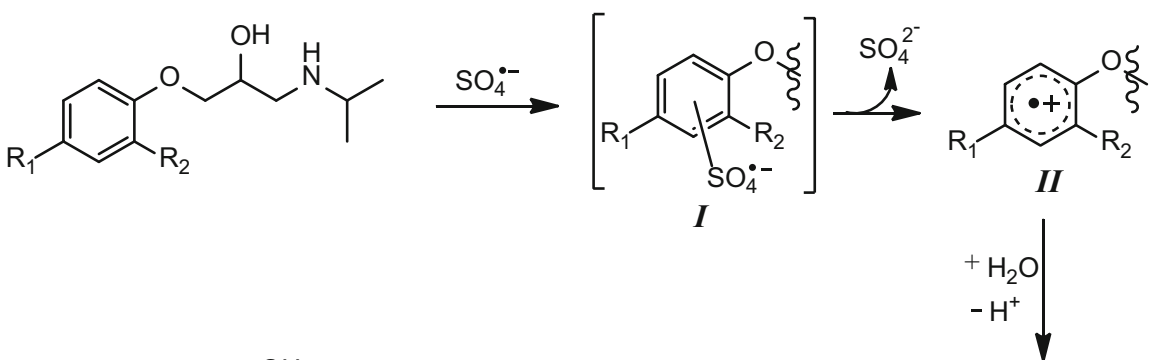<smiles>[R]C1=CC=C(O[Si])C([R2])C1O</smiles><smiles>[R]c1ccc(OCC(O)CNC(C)C)c(O)c1[R2]</smiles>

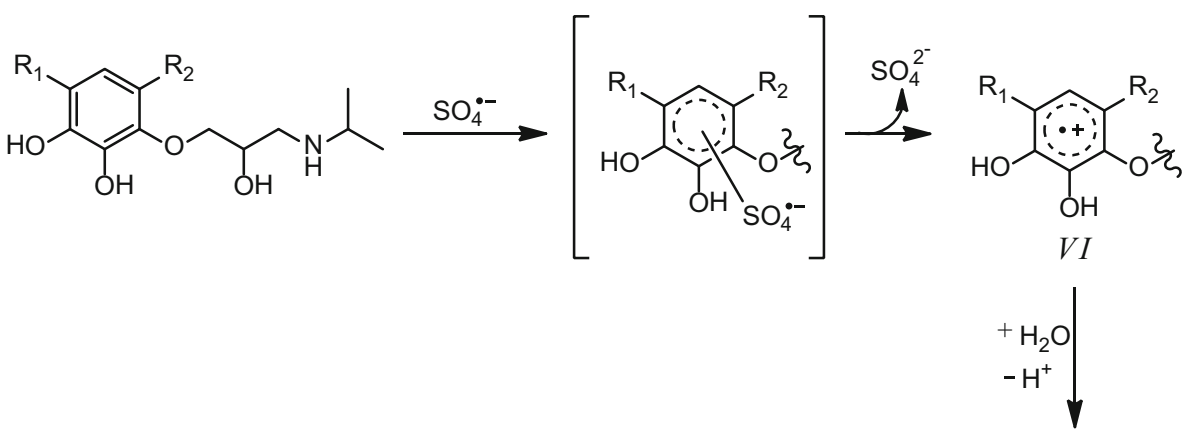<smiles>[R]C1=CC([R])=C(OCC(O)CNC(C)C)C(O)(O)C1O</smiles>

Met-317 / Ace-386<smiles>[Z20]Oc1c([R])cc([R])c(O)c1C(=O)O</smiles>

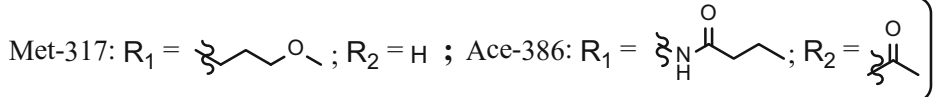

were reported. Instead of aromatic ring-hydroxylated and aromatic ring-opening by-products, the $\mathrm{OH}$-based oxidation process also produced transformation by-products with hydroxylated and degraded aliphatic chain which is not detected in this study (Tay et al. 2011, 2013; Veloutsou et al. 2014). Therefore, this study further proved the selectivity of $\mathrm{SO}_{4}{ }^{-}$when reacting with organic compounds.

\section{Ecotoxicity of transformation by-products}

The ecotoxicity of transformation by-products was predicted using ECOSAR software developed by United States Environmental Protection Agency (USEPA). This program has been used by USEPA to predict the aquatic toxicity of new industrial chemicals in the absence of experimental data (Mayo-Bean et al. 2012). This software 
Fig. 4 Proposed mechanism for removal of methoxyethyl chain from metoprolol

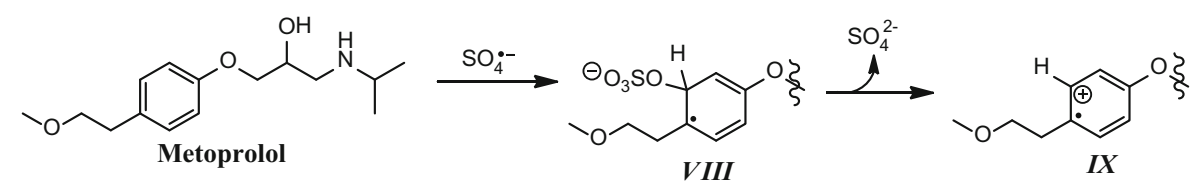

VIII

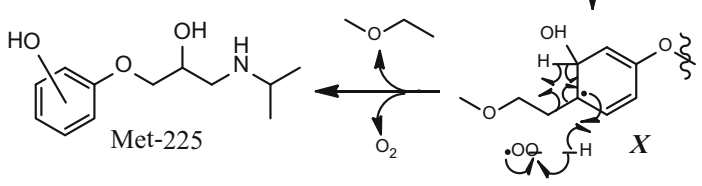

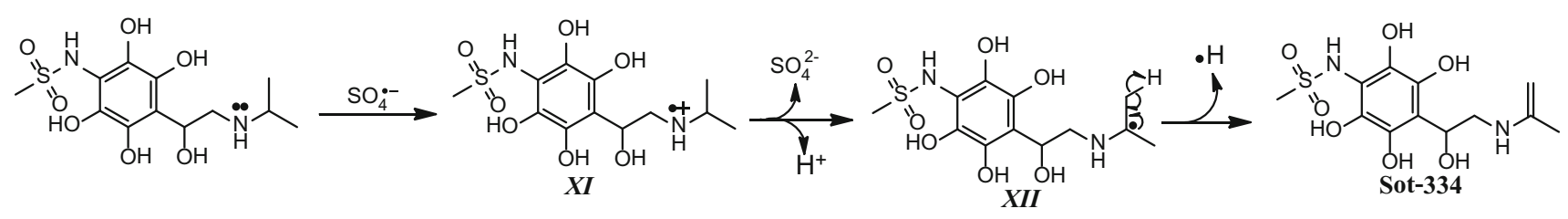

Fig. 5 Proposed mechanism for the aliphatic chain transformation pathway

Table 5 Predicted acute and chronic toxicity of the selected $\beta$-blockers and its transformation by-products

\begin{tabular}{|c|c|c|c|c|c|c|}
\hline \multirow[t]{2}{*}{ Compound } & \multicolumn{3}{|c|}{ Acute toxicity (mg/L) } & \multicolumn{3}{|c|}{$\mathrm{ChV}(\mathrm{mg} / \mathrm{L})$} \\
\hline & Fish $\left(\mathrm{LC}_{50}\right)$ & Daphnid $\left(\mathrm{LC}_{50}\right)$ & Algae $\left(\mathrm{EC}_{50}\right)$ & Fish & Daphnid & Algae \\
\hline Acebutolol & 1473 & 668 & 617 & 132 & 61 & 94 \\
\hline Ace- 251 & 1322 & 590 & 544 & 117 & 54 & 80 \\
\hline Ace-368 & 4002 & 1671 & 1538 & 341 & 143 & 190 \\
\hline Ace-326 & 18,872 & 6758 & 6194 & 1474 & 509 & 516 \\
\hline Ace-342 & 25,861 & 9036 & 8276 & 1992 & 667 & 648 \\
\hline Ace- 217 & 81,783 & 24,661 & 22,486 & 5789 & 1609 & 1209 \\
\hline Ace-386 & 826,000 & 212,000 & 193,000 & 53,349 & 12,115 & 6898 \\
\hline Metoprolol & 413 & 206 & 191 & 39 & 21 & 37 \\
\hline Met-225 & 1653 & 715 & 659 & 144 & 63 & 89 \\
\hline Met-299 & 5725 & 2269 & 2086 & 474 & 186 & 225 \\
\hline Met-317 & 31,398 & 10,703 & 9795 & 2385 & 774 & 720 \\
\hline Met-191 & 352,000 & 91,702 & 83,244 & 22,904 & 5293 & 3087 \\
\hline Met-231 & 818,000 & 210,000 & 182,000 & 51,449 & 11,019 & 5789 \\
\hline Sotalol & 6521 & 2532 & 2326 & 534 & 204 & 238 \\
\hline Sot-224 & 50,027 & 15,827 & 14,452 & 3640 & 1075 & 878 \\
\hline Sot-240 & 145,000 & 41,786 & 38,050 & 9991 & 2629 & 1833 \\
\hline Sot-318 & 152,000 & 44,848 & 40,863 & 10,626 & 2872 & 2078 \\
\hline Sot-336 & 428,000 & 115,000 & 105,000 & 28,387 & 6848 & 4236 \\
\hline Sot-334 & 431,000 & 116,000 & 105,000 & 28,590 & 6886 & 4250 \\
\hline
\end{tabular}

calculates the ecotoxicity of chemicals by addressing both acute $\left(\mathrm{LC}_{50}\right.$ and $\left.\mathrm{EC}_{50}\right)$ and chronic $(\mathrm{ChV})$ effects on fish, daphnid and algae. $\mathrm{LC}_{50}$ represents the chemical concentration that kills $50 \%$ of the fish and daphnid population after 96 and $48 \mathrm{~h}$, respectively. $\mathrm{EC}_{50}$ represents the chemical concentration that results in a $50 \%$ reduction in growth of algae after $96 \mathrm{~h}$ exposure. Predicted acute and chronic toxicity of selected $\beta$-blockers and its transformation by-products are presented in Table 5. The results indicated that even though the treatment of the selected $\beta$ blockers produced various transformation by-products, almost all of these by-products were less toxic than the parent compound. Based on the information from the transformation by-products, the degradation of the selected 
$\beta$-blockers was found to start with hydroxylation and was followed by the aromatic ring-opening reaction. In general, the ecotoxicity of the transformation by-products was found to decrease with increasing of the degree of hydroxylation. The result also indicated that the formation of aromatic ring-opening by-products largely reduced the ecotoxicity of $\beta$-blockers. Therefore, it can be concluded that the ecotoxicity of the selected $\beta$-blockers could be reduced using SR-AOP by producing more polar byproducts.

\section{Conclusion}

In this study, the kinetics and mechanisms for the reaction between acebutolol, metoprolol and sotalol with $\mathrm{SO}_{4}{ }^{-}$ were evaluated. The obtained $K_{\text {app }}$ showed that the selected $\beta$-blockers reacted with $\mathrm{SO}_{4}{ }^{-}$with the magnitude of $1.0 \times 10^{10}-3.0 \times 10^{10} \mathrm{M}^{-1} \mathrm{~s}^{-1}$. Based on the identified transformation by-products, the degradation of $\beta$-blockers by $\mathrm{SO}_{4}{ }^{-}$was mainly found to proceed through hydroxylation reaction. During SR-AOP, the mineralization of $\beta$ blockers can proceed through the formation of hydroxylated by-products followed by the aromatic ring-opening reaction. On the other hand, oxidation of the aliphatic chain was also observed. In conclusion, $\beta$-blockers can react favorably with $\mathrm{SO}_{4}{ }^{-}$; however, SR-AOP also produced various transformation by-products. The result from the ecotoxicity assessment indicated that almost all the proposed transformation by-products were less toxic as compared with its parent compound. Therefore, SR-AOP could be a clean method for the treatment of $\beta$-blockers in water.

Acknowledgments This research was financially supported by Ministry of Higher Education Malaysia (FRGS FP043-2013A).

\section{References}

Anipsitakis GP, Dionysiou DD, Gonzalez MA (2006) Cobalt mediated of peroxymonosulfate and sulfate radical attack on phenolic compounds-implications of chloride ions. Environ Sci Technol 40:1000-1007

Benner J, Salhi E, Ternes T, Gunten UV (2008) Ozonation of reverse osmosis concentrate: kinetics and efficiency of beta blocker oxidation. Water Res 42:3003-3012

Bundschuh M, Hahn T, Ehrlich B, Höltge S, Kreuzig R, Schulz R (2016) Acute toxicity and environmental risks of five veterinary pharmaceuticals for aquatic macroinvertebrates. Bull Environ Contam Toxicol 96:139-143

Burkina V, Zlabek V, Zamaratskaia G (2015) Effects of pharmaceuticals present in aquatic environment on Phase I metabolism in fish. Environ Toxicol Phar 40:430-444

Cizmas L, Sharma VK, Gray CM, McDonald TJ (2015) Pharmaceuticals and personal care products in waters: occurrence, toxicity, and risk. Environ Chem Lett 13:381-394
Gao Y, Gao N, Deng Y, Yin D, Zhang Y (2015) Degradation of florfenicol in water by $\mathrm{UV} / \mathrm{Na}_{2} \mathrm{~S}_{2} \mathrm{O}_{8}$ process. Environ Sci Pollut R 22:8693-8701

Guan Y, Ma J, Li X, Fang J, Chen L (2011) Influence of pH on the formation of sulfate and hydroxyl radicals in the UV/peroxymonosulfate system. Environ Sci Technol 45:9308-9314

Huggett DB, Khan IA, Foran CM, Schlenk D (2003) Determination of beta-adrenergic receptor blocking pharmaceuticals in United States wastewater effluent. Environ Pollut 121:199-205

Ji Y, Fan Y, Liu K, Kong D, Lu J (2015) Thermo activated persulfate oxidation of antibiotic sulfamethoxazole and structurally related compounds. Water Res 87:1-9

Ji Y, Xie W, Fan Y, Shi Y, Kong D, Lu J (2016a) Degradation of trimethoprim by thermo-activated persulfate oxidation: reaction kinetics and transformation mechanisms. Chem Eng J 286:16-24

Ji Y, Kong D, Lu J, Jin H, Kang F, Yin X, Zhou Q (2016b) Cobalt catalyzed peroxymonosulfate oxidation of tetrabromobisphenol A: kinetics, reaction pathways, and formation of brominated byproducts. J Hazard Mater 313:229-237

Khalit WNAW, Tay KS (2016) Aqueous chlorination of acebutolol: kinetics, transformation by-products, and mechanism. Environ Sci Pollut Res 23:2521-2529

Liu J, Lu G, Xie Z, Zhang Z, Li S, Yan Z (2015) Occurrence, bioaccumulation and risk assessment of lipophilic pharmaceutically active compounds in the downstream rivers of sewage treatment plants. Sci Total Environ 511:54-62

Maszkowska J, Stolte S, Kumirska J, Łukaszewicz P, Mioduszewska K, Puckowski A, Caban M, Wagil M, Stepnoski P, BiałkBielińska A (2014a) Beta-blockers in the environment: Part I. Mobility and hydrolysis study. Sci Total Environ 493:1112-1121

Maszkowska J, Stolte S, Kumirska J, Łukaszewicz P, Mioduszewska K, Puckowski A, Caban M, Wagil M, Stepnoski P, BiałkBielińska A (2014b) Beta-blockers in the environment: Part II. Ecotoxicity study. Sci Total Environ 493:1122-1126

Matta R, Tlili S, Chiron S, Barbati S (2011) Removal of carbamazepine from urban wastewater by sulfate radical oxidation. Environ Chem Lett 9:347-353

Mayo-Bean K, Moran-Bruce K, Nabholz JV, Meylan WM, Howard PH (2012) Operation manual for the Ecological StructureActivity Relationship Model (ECOSAR) class program. Risk Assessment Division, U.S. EPA

Niemuth NJ, Klaper RD (2015) Emerging wastewater contaminant metformin causes intersex and reduced fecundity in fish. Chemosphere 135:38-45

Pomati F, Netting AG, Calamari D, Neilan BA (2004) Effects of erythromycin and ibuprofen on the growth of Synechocystis sp. And Lemna minor. Aquat Toxicol 67:387-396

Romero V, González O, Bayarri B, Giménez J, Esplugas S (2015) Performance of different advanced oxidation technologies for the abatement of the beta-blocker metoprolol. Catal Today 240:86-92

Santos LHM, Gros M, Rodriguez-Mozaz S, Delerue-Matos C, Pena A, Barceló D, Montenegro MCBSM (2013) Contribution of hospital effluents to the load of pharmaceuticals in urban wastewaters: identification of ecologically relevant pharmaceuticals. Sci Total Environ 461-462:302-316

Sun L, Wang S, Lin X, Tan H, Fu Z (2016) Early life exposure to ractopamine causes endocrine-disrupting effects in Japanese Medaka (Oryzias latipes). Bull Environ Contam Toxicol 96:150-155

Sun J, Luo Q, Wang D, Wang Z (2015) Occurrences of pharmaceuticals in drinking water sources of major river watersheds, China. Ecotox Environ Saf 117:132-140

Swaraga MS, Adinarayana M (2003) Kinetics and mechanism of protection of adenine from sulphate radical anion by caffeic acid under anoxic conditions. Indian J Biochem Biophys 40:27-30 
Tay KS, Madehi N (2014) Ozonation of acebutolol in aqueous solution: ozonation by-products and degradation pathway. Sep Purif Technol 135:48-63

Tay KS, Madehi N (2015) Ozonation of ofloxacin in water: byproducts, degradation pathway andecotoxicity assessment. Sci Total Environ 520:23-31

Tay KS, Rahman NA, Abas MRB (2011) Characterization of atenolol transformation products in ozonation by using rapid resolution high-performance liquid chromatography/quadrupole-time-of-flight mass spectrometry. Microchem J 99:312-326

Tay KS, Rahman NA, Abas MRB (2013) Ozonation of metoprolol in aqueous solution: ozonation by-products and mechanisms of degradation. Environ Sci Pollut Res 20:3115-3121
Tsitonaki A, Petri B, Crimi M, Mosbæk H, Siegrist RL, Bjerg PL (2010) In situ chemical oxidation of contaminated soil and groundwater using persulfate: a review. Crit Rev Environ Sci Technol 40:55-91

Veloutsou S, Bizani E, Fytianos K (2014) Photo-Fenton decomposition of $\beta$-blockers atenolol and metoprolol; study and optimization of system parameters and identification of intermediates. Chemosphere 107:180-186

Xu L, Yuan R, Guo Y, Xiao D, Cao Y, Wang Z, Liu J (2013) Sulfate radical-induced degradation of 2,4,6-trichlorophenol: a de novo formation of chlorinated compounds. Chem Eng J 217:169-173

Zhang R, Sun P, Boyer TH, Zhao L, Huang C (2015) Degradation of pharmaceuticals and metabolite in synthetic human urine by UV, $\mathrm{UV} / \mathrm{H}_{2} \mathrm{O}_{2}$, and UV/PDS. Environ Sci Technol 49:3056-3066 